
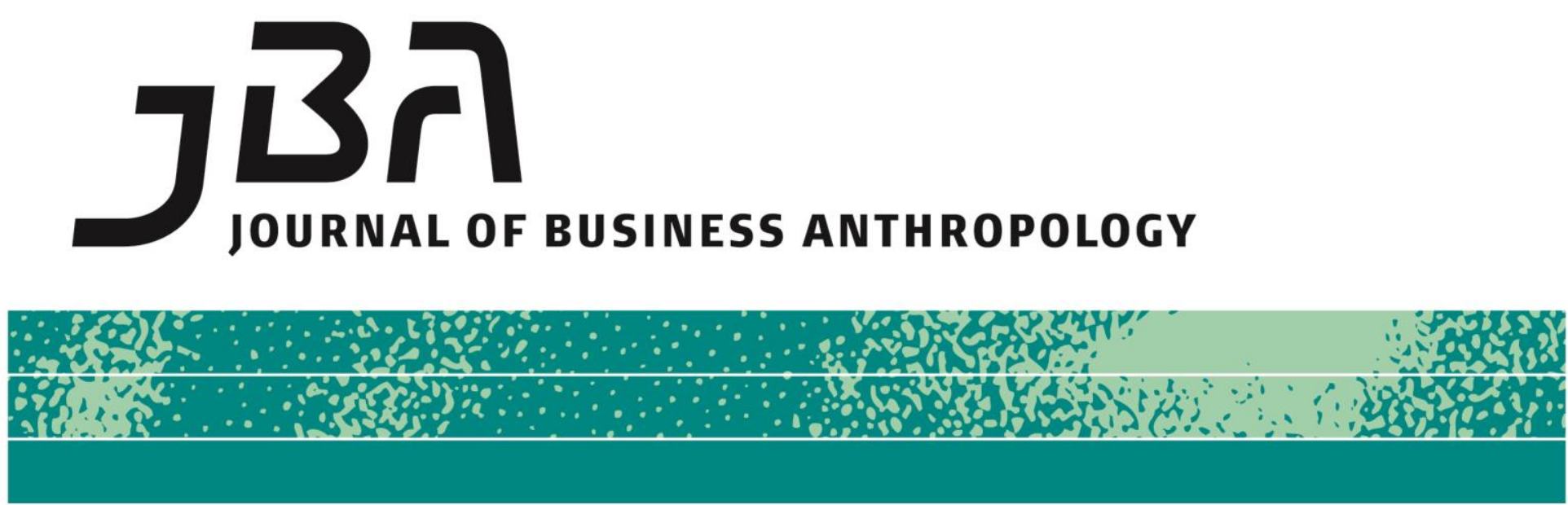

\title{
Fieldwork in a Foreign Culture: Business
}

\author{
Elisabeth Powell
}

The business immersion was definitely trial by fire, just doing it and figuring it out as you went along, doing things I had never done in my life. It's like doing fieldwork to understand the tropes of business and the ways things are organized and how that whole business world thinks, their view of the world - so that one can contribute to it in a way that maintains one's anthropological identity, but can be helpful to business needs. I think that takes a long time. (Denny 2014: Princeton University thesis interview)

Page 1 of 18

JBA 10(2): 368-385 Fall 2021

(C) The Author(s) 2021 ISSN 2245-4217

www.cbs.dk/jba

$10.22439 /$ jba.v10i2.6 418

anthropologists transitioning from their academic cultures into their new business contexts, either as employees or consultants. In my previous article, I explored how and why twenty anthropologists on academic tracks shifted course and made their ways into the world of business.

In this article, I will analyze anthropologists' transitions and integrations into their new cultural contexts of business, based on the interviews I conducted with twenty anthropologists in business. What was hardest about their transitions? What challenges do they continue to face in their business roles? Based on this analysis, I hope to illustrate how anthropologists transitioning into business apply (and modify) their anthropological education, training, and perspectives to create value for businesses and for themselves (and, as I will argue in forthcoming 
articles, for academic anthropology).

In my conversations, every anthropologist remarked on the novelty of their business contexts. After detaching from academia, they described entering a foreign world: "business." "Business" entails a hitherto unknown context of unique motivations, value systems, language, hierarchies, power systems, political orientations, expectations, goals, and sociocultural norms. Effectively, "business" represents a distinct culture unto itself. To succeed in their careers, anthropologists have to first understand their new sociopolitical, cultural contexts, and their locations within those contexts. Academically oriented and socialized anthropologists have to learn a new language, new social structure (institutions, hierarchies, forms of power, etc.), and value systems.

Most graduates from traditional academic anthropology programs have not been trained in business language, norms and customs; however, they have been expertly trained (perhaps better than any other discipline) in how to make sense of foreign cultural contexts. Denny captured this process of understanding well when she described her sense-making as "fieldwork" (2014).

Indeed, the experience of anthropologists transitioning into business closely mirrors that of academic anthropologists who go out into the field to understand a foreign culture through participant-observation within that culture. This research method is a hallmark of traditional academic anthropology. Remarkably, these anthropologists are doing just that in business contexts: they are entering an unknown cultural context and engaging in full immersion participant-observation. However, the parallels with traditional academic anthropology diverge from there.

These anthropologists will not be returning from the field to their own familiar academic cultures. They must understand their new context not just for the "sake of the knowledge," but in order to do something about that knowledge. Namely, they must use the knowledge to determine what is expected of them, and tailor their research and communication approaches accordingly to ensure that they create sustained value for their employers and for themselves. What will become clear is that the research and communication norms of academia are profoundly different from - and perhaps in tension with - business interests, expectations, language and ethics.

A critical component of anthropologists' success in business hinges upon their grasping how to be "heard," how to "count" in business, and how to add "value" and be deemed "valuable." As will become evident, the anthropologist's effective "translation" of fieldwork into understanding and integrating into their business cultures, and effectively communicating their anthropological approaches and results, are critical to their success. 
In an article he wrote for the Anthropology Newsletter, Erickson captured the task for anthropologists in business: “Anthropology can't be relevant by itself. It requires participants on the outside to bestow relevance on it" (1999:17). Because business is overwhelmingly collaborative, inter-relational, multidisciplinary, and hierarchical in nature, it is essential that the anthropologist understand the worldview of all business cultural constituencies in order to make anthropology "relevant."

Anthropologists must translate their experiences and perspectives in order to effectively interact and communicate with their peers, bosses, subordinates, customers, consultants, and other categories of business "natives." This translation inevitably means transforming the methodological tools and conceptual resources of academic anthropology into terms and forms that are relevant to non-anthropologist business people. Remarkably, despite these acts of translation, traditional anthropological theory and analytical perspectives remain essential in how my informants add value in business.

\section{Understanding Business Culture}

These anthropologists' academic training prepared them with phenomenal theoretical expertise and analytical skills, but many were not introduced to even the most basic business precepts, principles, skills or language. For example, Hill recalled having to read "Business 101" books to help him tackle fundamental business questions: "How much would you charge for your services? How much would you charge knowing that you might have some tax overhead, or you might have to buy some equipment to do those things? Who is liable if one of the things you told someone to do goes horribly wrong?" Reflecting on his academic anthropological education, Hill noted, “The business side they don't teach you about at all. I think that's a big failure" (Hill 2014: Princeton University thesis interview). Given this lack of business education, an enormous amount of learning and acclimation must happen upon entering business.

In describing their transitions into business contexts, my interviewees spoke about their experiences essentially from a "two cultures" perspective: leaving a culture of academia and entering a new foreign culture of business. As noted, Denny likened her task to that of "fieldwork" in any other academic anthropological research context (2014). According to McCabe, this process of "learning how to think like business people think," of "learning their language and their worldview, how they look at things, what's important to them," was the most difficult aspect of her transition into business. Similarly, Baker's biggest challenge in his consulting work has not been producing great anthropological insights, but "becoming a business person" (McCabe 2014: Princeton 
University thesis interview).

Capturing the "two cultures" perspective, Squires described businesses as having "their own cultures and their own language." Though entering business with a robust theoretical framing and analytical expertise, she was "clueless" about the business realm: "Often, an anthropologist does not know how to navigate around business, how to talk to people, how to put a report together that is accessible" (Squires 2014: Princeton University thesis interview). She described her transition into business as the start of her "second career of learning," and her understanding of business as a process that happened "over time" (2014). Through "being there" (in true anthropological, Geertzian fashion), she discovered the motivations and "goals" of the business (Geertz 1988). Her characterization of her integration into business is strikingly similar to the traditional model of anthropological participant-observation and immersion. Far from "clueless," I contend that she and all of my informants were remarkably well prepared to understand their new cultural contexts. Anthropology is not about already knowing the relevant knowledge, but about knowing how to figure it out.

In the remainder of this piece, I will describe and analyze my informants' descriptions of their challenges understanding and integrating into new cultural contexts, with particular emphasis on new business values, social roles and power hierarchies, and business language and communication norms. On the one hand, their success transitioning into these new cultures was made more difficult because of their counter-cultural backgrounds as academic anthropologists. On the other hand, I posit that their anthropological cultural orientation and academic training equipped them fantastically for making sense of and adding value in their new business contexts.

\section{Identifying Business Values}

Understanding the values, objectives, and motivations of the business is essential for anthropologists to know "what counts" in business, so that they can produce work that is valuable (and perceived as such by their employers). "What counts" in business differs in many ways compared to "what counts" in academia, and anthropologists must understand those differences. Accordingly, they must modify their anthropological approaches to cater to their new business value systems.

Baker offered the seemingly extreme view that business has only one motivation and priority: profits (Baker 2014: Princeton University thesis interview). By implication, anthropological work only "counts" as valuable to the extent that it directly impacts the company's bottom line. Thus, Baker contended that rather than prioritize the depth of "anthropological insight and holistic perspective," anthropologists who want to be successful in business should tailor their role and work to 
achieve business goals and make an economic impact (2014). According to Baker, this means translating anthropological insights into "actionable results" (e.g., what companies can "put into the marketplace") (2014).

This translation into practical business implications was a theme touched on by many of my informants. Baker's comments reflect the perceived need in business contexts to transcend "understanding" to get to the "so what" of the understanding. Without translation into tactical next steps, really good anthropological insights are not relevant in business. However, as will become clear, most of my informants described their added value as critically hinging upon their depth of theoretically grounded anthropological perspectives and insights.

Mikkel Brok-Kristensen described the biggest challenges faced by anthropologists in business as being two-fold. First, the anthropologist must "truly understand and appreciate what it means to be a business" (Brok-Kristensen 2014: Princeton University thesis interview). To be in a position to really add value, the anthropologist must understand the challenges and obstacles that businesses face - of needing to run factories and produce products, for example. These business realities are not the realities of academic anthropology.

Second, Brok-Kristensen explained, "You need to make yourself relevant, and you can only be relevant if you make yourself go beyond trying to clarify things and show how you can act on those things." Further, he described that as a "universal challenge" for all consultants, but especially those with backgrounds in academic anthropology who are not taught to take this extra step in applying the knowledge produced, particularly under short time frames (2014). Indeed, the apparent business value of analytical speed is one that differs notably from the long-term orientation of academic anthropology. Learning to work under short time constraints was a commonly articulated challenge in their integrations and ongoing roles in business.

Smith, who works at a large technology company, described the challenges she faced in learning how to provide compelling justifications for her corporate research projects. In academia, she explained that enhanced understanding "counts" as justification for a research project: "'this is really interesting and it will add to our knowledge' is a good reason to do research." However, in industry, "really interesting" and "add[ing] to our knowledge" are not sufficient reasons for devoting resources to conduct research, because "understanding is not the ultimate goal of a business context" (Smith 2014: Princeton University thesis interview).

Instead, in industry, the critical questions are: "Of what use is that to me? How does that help me do something?" In any given research question she is pursuing, her company's research questions (and therefore what Smith must address) are: "How does this lead us to 
something that has relevance for the kinds of technologies that we make? What kinds of technological interventions should we make based on this knowledge?" (2014) The insights are merely inputs to the final answer, not the final answers in and of themselves.

Similar to Baker and Brok-Kristensen's experiences, Smith's employer cares solely about the "so what" of any research findings, which they use to "intervene" in their consumers' lives with a new product, service or business strategy. Success in business requires translating knowledge into the business implications of that knowledge. Interestingly, the anthropologists must make their "product" (their interpretations, not just methodologies) "culturally relevant" to the business, which is trying to make its products, services or messaging "culturally relevant" to its consumers. Clearly, there are multiple layers of "cultural relevance" at stake in business, which anthropologists are expertly trained to understand.

Another key challenge for anthropologists adjusting to business contexts lies in the realities of business timelines. Hill struggled to adapt to the short time frames and "internal rhythms" of his business, and the implications of those time restrictions on the nature and outcomes of his work. He would be given only two months (compared to the two years he might have in an academic context) to fully understand and design for a new, foreign community of people. He noted that the "short term demand and design deliverables" in business differed notably from the longerterm approach to research taken in academia (2014). And, he was lucky to get two months instead of two weeks!

He went on to explain that in business, he has had to learn how to develop a "best guess" based on the research he was able to do given limited resources. He recalled struggling to resist providing all reasons why something might not work, or everything that might be worth considering before trying something. This depth and thoroughness had been integral to his work in academia, but his employers needed solutions to their problems. He had to learn to deal "psychologically" with being "good enough" and settling with his "best guess," for another project would be awaiting him. It is notable that the academic value of acknowledging contingencies and plausible alternative perspectives directly conflicts with the business value for a "quick solution" or "the right answer" (2014).

In this example, Hill's academic training and orientation conflicted with his business demands, so he had to modify in order to be "successful" in his new context. Hill noted that his experiences in applied anthropology during his academic years helped him to integrate more rapidly and effectively than otherwise would have been the case. During his academic studies, his fieldwork exposed him to "explaining work and material culture," as well as to projects where he faced the reality of: 
"People are dying. I need to do something to help them" (2014). Here, insights had to be turned into actions.

Sunderland also reflected that the fast pace and expectations of the business world have been particularly challenging in her consulting work. She described how the research model in business profoundly differs from that in academia, and she has had to learn to adjust accordingly. In particular, she noted that "ethnography in the business world is not the year-long ethnography" characteristic of traditional academic anthropology. Rather than having the "luxury" of a year to research and a year to reflect on and write about the research, she now gets "two weeks to study, two weeks to write up" (Sunderland 2014: Princeton University thesis interview). By implication, she has had to transform her academic methodological tools to fit her cultural context in business. Notably, though methodology might look different, many of my informants seem to use characteristically academic theoretical and analytical perspectives to make sense of their research data.

Clearly, key values regarding what "counts" as "valuable" knowledge differ profoundly in business and academia. In each context, there are different uses for knowledge. In a sense, then, anthropologists must "unlearn" the academic value of knowledge for the purpose of better understanding humanity and, instead, learn to tailor their work according to a new business value of knowledge for the purpose of "actionable deliverables."

Anthropologists must also adjust to the business value (requirement) of speed in the production and implementation of knowledge. This orientation profoundly differs from anthropology's characteristic slowness, which usually indexes cultivation of real relationships as the real tools of ethnographic understanding. Clearly anthropologists in business face a profoundly different set of values in business than they did in academia. Thus, they must learn and adjust.

\section{Mapping the Sociopolitical Landscape}

A critical, though often overlooked, cultural element that anthropologists in business must understand is the novel sociopolitical structure of the business, and their social role within that structure. Anthropologists in academic contexts typically work alone or in a group of similarly oriented anthropologists. By contrast, anthropologists in business must integrate effectively into a team of individuals with widely differing cultural backgrounds, motivations, "languages" and worldviews (e.g., an engineer versus a marketer versus a product designer). Anthropologists must understand where each of their team members is "coming from" so that they can effectively communicate and collaborate with them. Further, anthropologists in business must understand the sociopolitical and cultural context of those they report to in order to meet their expectations 
and ensure success in their roles.

It is important to note that in every conversation, the "translation" burden fell upon the anthropologist. Though none of them articulated a reason for this, I believe that it is intimately tied to their relative position of power (or lack thereof) as employees. Since they were the ones hired rather than hiring, they are in a position of dependence upon their employers: they must be deemed "valuable" by their employers in order to continue receiving their paychecks.

The anthropologist's employment depends upon not just meaningful anthropological research and insights, but successful communication of those insights. Importantly, successful communication means tailoring the content, narrative, and even form to whomever is receiving their reports. Thus, their challenges in transition and translation are embedded in their new social roles and power hierarchies, and they cannot be understood without considering the broader sociopolitical context of their jobs.

Providing a consultant perspective, Denny explained that in her projects, the knowledge produced and delivered to her employers "does not exist in a vacuum." Rather, she understands that to craft "deliverables" that are useful and valuable for clients, she must understand the position of her employers within their sociopolitical contexts. She told me that clients want and need more than just "insights into how to solve their problem." They need "insights into how to solve their problem...that they can achieve buy-in with" (Denny 2014: Princeton University thesis interview).

Thus, Denny noted how critical it is to recognize that "clients live within social relationships and conversations" (2014). Therefore, for her to be successful in her engagement with the client, Denny must understand her employer's broader context and craft her final "deliverables" with that context in mind. Thinking back to my economic anthropology courses, it makes sense that products are not consumed by isolated individuals but by individuals embedded in broader contexts that shape the consumption of those products.

Also employed within a consulting context, Brok-Kristensen explained that in his projects, he is often responsible to a company's CEO or other high-ranking employee. He reflected that he must understand that individual's "particular role" within the company's "power hierarchy," and the individual's "particular stake in that company" (2014). Fortunately, understanding and catering to the client's sociopolitical context should be an endeavor in which anthropologists in particular excel. After all, their academic anthropological educations train them to understand and attend to individuals' broader sociopolitical and cultural contexts. 
While Denny and Brok-Kristensen both emphasized the importance of understanding the external sociopolitical contexts of their clients, Malefyt reflected on the importance of understanding the internal micro-cultures and power hierarchies within his advertising agencies. He touched upon the reality that being smart and having great ideas matter only to the extent that they are communicated effectively to colleagues and employers. The integration into social employment contexts is especially challenging for anthropologists coming out of academia because they tend to conduct their research alone: "They go off to 'their people,' and they're the lone anthropologist" (Malefyt 2014: Princeton University thesis interview).

However, business involves "working with other people, talking, socializing, contributing ideas, building off other people" (2014). Indeed, in their book, Advertising and Anthropology (2012), Morais and Malefyt devoted an entire chapter to the construct of meetings as the central sociocultural contexts that "constitute a central event around which [advertising] agency life is focused, and they contain the defining attitudes, behaviors, and symbols of the client-agency relationship" (19). In fact, Malefyt explained that his work in advertising is "really about creating relationships" (2014). Malefyt described the importance of his role as a researcher in mediating between and communicating with the various departments within the agency, like the account team and creative team, each of which has their own unique "subculture" (2014).

Similarly, Smith reflected on the challenges of having to work in collaborative, multidisciplinary contexts, and the resulting need to understand multiple worldviews in order to successfully communicate (crucial to the anthropologist's ability to add value). Depending on the project, she might be working with a designer or an engineer, each with a unique "language" and set of shared assumptions (2014). For example, she explained that to a designer, concepts that would be meaningful to other anthropologists, like "narrative" and "self-construction," are "not useful." So, for her, it is a challenge "trying to figure out, "How does this interesting knowledge become useful to somebody whose agenda is to design something?'” A critical component in this is "translating" what would make sense in academic anthropology contexts into terms relevant to designers, as well as understanding what the designers' job expectations involve (2014).

Brok-Kristensen highlighted another challenge faced by academic anthropologists entering collaborative business contexts. He observed that often anthropologists struggle with being so "in love" with their own ideas that they fail to truly listen to others (2014). Similarly, Mack found it difficult in business to "not always be right." She noted that within academia, she learned the importance of arguing your point, but that in business, you have to learn to "finesse." She explained "even when you know that you are right, you can't make other people feel like you are 
doing that" (Mack 2014: Princeton University thesis interview). Moveover, business values building on half-baked ideas together, while academic anthropology is often a more individual pursuit of perfection. Clearly, business values and academic values in this case are not aligned.

These challenges in adjusting to novel work contexts - power hierarchies, multidisciplinary and collaborative social environments support my thesis that business is effectively its own unique culture. Anthropologists enter that unknown culture as a foreign outsider, untrained in how to be an effective member of the culture but trained in how to figure that out. To succeed in their new roles, anthropologists must understand the dynamics of their new sociocultural system, as well as the worldviews of each of the constituencies in that system. Then, they must tailor their approaches to work and communication in order to be productive, value-adding members of their new business cultures.

\section{Talking the Talk}

Effective communication is perhaps the biggest challenge for anthropologists transitioning into business. In academia, anthropologists generally write for and speak to others that share a common knowledge of learned anthropological concepts and styles of communication. However, their new social locations put them in collaboration with nonanthropologists who do not share the lexicon of academic anthropology. Thus, anthropologists must dramatically shift both their vocabulary and delivery of knowledge in business in order to be intelligible, which is crucial for them to be deemed valuable.

These challenges in translating their learned anthropological concepts and style of communication, and the importance of effectively doing so, were articulated by every one of my informants. For example, Mitchell noted that rather than deliver her work products in prose, she now translates her insights into a presentation that effectively tells a story - in PowerPoint! Incorporating pictures and videos into very visual communications enables her to communicate successfully with her multidisciplinary teams and employers (Mitchell 2014: Princeton University thesis interview).

Indeed, a number of my informants reflected upon the shift in knowledge presentation from academic prose and papers to compelling visuals and stories. Bell explained that she had to learn "how to stand up and make a point without having the words finely written in front of [her]." She explained that becoming comfortable with that form of presentation, which profoundly differs from the communicative norms in academia, is "actually a skill” (Bell 2014: Princeton University thesis interview).

Every single business anthropologist described learning the 
"language of business" as if it was a foreign language. Indeed, my informants conveyed powerfully the "two cultures" perspective when they talked about their challenges in understanding the "language of business" and in translating the "language of anthropology." For example, Sachs-Chess said that learning to speak in the language of business was the most difficult aspect of her transition into her business career: "I was coming from an academic background. I didn't necessarily know how to say things that people could hear. It was a different language" (SachsChess 2014: Princeton University thesis interview).

It is striking that so many of my informants discussed their transitions as putting them into a context in which everyone spoke a "foreign language," and in which their language grounded in academic anthropology was neither intelligible nor meaningful to those foreigners. Technically, everyone was speaking English in most of these contexts, yet the "anthropological English" and "business English" are represented as distinct, even "foreign" languages - an indication of separate cultures.

Within their need for cultural translations, several informants emphasized the challenge in finding the delicate balance between communicating effectively to cause business colleagues and employers to understand them while maintaining a unique anthropological voice and perspective. Denny's opening quote in this piece perfectly captures this challenge of effectively satisfying "business needs" while maintaining one's "anthropological identity" (2014). Trained in linguistics, Denny explained that the "language of business" is quite different than "the language of anthropologists." She described business language as including "psychological terms" or "marketing terms" or "consumer terms" - words like "motivations," "unfulfilled needs," and "desires." This language contrasts with what anthropologists think about: consumers' "practices and their behaviors and their ideas and cultural processes and symbols." She maintained that clients hire her for this unique "anthropological point-of-view," and that losing that language means losing her unique contribution (2014).

In fact, Denny recalled being frustrated by projects with clients who required her to take on "their language" and way of thinking for the project to be deemed "successful." From Denny's perspective, those projects were a "failure" because she had failed to make them think differently about whatever "they're producing, or developing, or selling, or innovating." This is a striking example in which Denny's "goals" and definitions of "success" clearly transcend merely making money for the client. Instead, she seems committed to exposing them to, and having them understand and appreciate, her academic anthropological perspective.

Denny also noted that the challenge in finding a balance between the "language of business" and "language of the anthropologist" can lead 
to the opposite outcome, which is "equally frustrating." She told me that in some cases, a project was not ultimately "successful" because she "got caught up in what [she] thought was so interesting" without "solving their problem" (2014). Clearly, Denny struggles in striking a balance between her academic anthropological perspective and cultural orientation, and the cultural context of business.

The comments by Denny and several other informants reflect the challenge faced by anthropologists who want to make an impact and add value in business as anthropologists. Anthropologists must assimilate "enough" in order to be "heard" by employers: if they use their anthropological language and style of communication with clients, they risk "alienating" the client and being rejected entirely. Yet, if they fully assimilate, then they are not causing clients to see through an anthropological lens.

Later in this article, I will take up these ideas again in the context of the essential role anthropological theory plays in many of my informants' work and sense-making, but also the challenges this poses in communicating their perspectives and rationales to non-anthropologists. For the moment, I want to note that clearly a delicate balance must be struck by those who want to retain their jobs without sacrificing their anthropological identities.

Similar to Denny, Brok-Kristensen reflected on the tension arising from the "different languages" spoken by anthropologists and by most business people, combined with his commitment to maintaining his anthropological voice. He noted that he purposely uses language "foreign to that of [his] clients," and he tries not to "get too caught up in the vocabulary of the world of business." He articulated an important distinction for himself and his fellow social scientist colleagues between understanding the "vocabulary of business" and speaking it. To BrokKristensen, using anthropological language with clients is critical because "business lingo is contributing to the mis-readings of the world." However, he struggles to strike the balance between being intelligible to clients and completely forfeiting his anthropological language (2014).

Of the issues in "translations" from an anthropological language and cultural orientation to a form for business people, anthropological theory seems most difficult to communicate. After several courses studying dense anthropological theory that took hours of analysis to even begin to understand, I am not surprised that this aspect of academic anthropology is especially difficult to convey to non-anthropologists. Nonetheless (and, perhaps, because of its uniqueness), anthropological theory is absolutely critical to many of my anthropologists' work and contributions in business.

Squires described having to actively learn how to communicate theory in a way that business people could hear and understand. Indeed, 
she expressed difficulty learning to use "theory in a way that isn't intimidating." Notably, however, still using theory! She explained that she actually took writing classes to learn how to make complex language and concepts clearer, less "intimidating," and more accessible. Importantly, she was able to learn how to make theories comprehensible without "simplifying": "you can still maintain a complexity that is necessary to explain a particular theory without necessarily being complex in your communications" (2014).

However, this style of writing and communicating is profoundly different from the norms of communication in academia. A large reason for this is that in business, anthropologists are working on multidisciplinary teams, with individuals that do not share their academic language, perspective, assumptions or training. Thus, they must strike a common linguistic and intellectual ground.

Similarly, Mitchell contrasted her personal utilization of theory in analysis of ethnographic data with her (non)use of theory in reporting to her employers. Though theories are "always an underpinning" to her work in business (she noted "structuralism" and "grounded theory" as being particularly useful), she discovered that her colleagues and bosses wanted "more tactical information." So, she does not bring theory "to the fore" in communicating her work, because her colleagues "didn't understand it, and they didn't care about it." Moreover, communicating theory explicitly could be "alienating" to business people (2014). Thus, Mitchell reflected that a critical aspect of her work involves being able to "translate" her approach and interpretations to her audience.

Bell captured well the challenges faced by anthropologists in business who are committed to maintaining their anthropological distinctiveness and value. Bell noted that when presenting an issue recently she "gave kind of an anthropological critique using a classic anthropological tool of 'defamiliarization': to take a very common thing that they thought they all knew and give them a completely different point of view about it." However, reflecting many of my informants' experiences, she explained that she had to translate the theory into terms meaningful to non-anthropologists: "You couldn't do it by calling out what specific theoretical tools that you were using to unpack that idea" (2014).

Indeed, many of my informants struggled to translate specific anthropological theories into intelligible, meaningful terms for nonanthropologists. Bell noted that anthropologists in business must "learn to communicate beyond a shared canonical vocabulary with practitioners to engage and align logically with people" (2014). When done well, the successful explanations of these theoretical concepts can enlighten business people and add unique value.

Though Sherry described theory as integral to the analysis of his research data, he explained that he "treads lightly" when bringing up 
theory with clients. He told me that clients want "something practical," rather than "a theoretical interpretation" of research findings. Therefore, he only incorporates theory in final client presentations to the extent that it "illuminates" his message. However, he explained that when he does explicitly make use of anthropological theories with clients, he always "translates the theory into examples and interpretation right away rather than beginning with the theory" (Sherry 2014: Princeton University thesis interview).

Similar to Sherry, Morais reflected upon the critical role of anthropological theory in his contributions in business, yet the tenuous communicative acts of conveying those theoretical concepts to clients. For example, he recounted an experience with a client when they were collaborating in a "brainstorming" or "ideation" session. During the conversation, he brought up the anthropological idea, "binary opposition." However, he noted that when introducing the concept, he was not "too heavy-handed" about it and did not even acknowledge that the term was "anthropological" or associated with Levi- Strauss. He explained that having clients think in terms of opposites might help them to "discover something about the category or their own thinking that would help them come up with fresh ideas" (Lévi-Strauss 1978).

Striking to me in this case, Morais may have been able to effectively teach his clients to apply an anthropological lens without explicitly calling the lesson anthropological! His comments also reflect a common theme around the usefulness of traditional academic conceptual resources introduced and employed without speaking in their technical terms - which would most likely prevent them from being "useful" in business.

Morais also recalled an experience in which he brought in the concept of "ritual" with a client during the first run of their presentation. He explained that the client was "fascinated," and asked him to incorporate more on ritual into the final version of the presentation. Moreover, Morais commented that his team "got more business as a result" of their discussion of "ritual" and its meaningful applications in the context of the client's products and brand (Morais 2014: Princeton University thesis interview: Princeton University thesis interview).

Similar to Morais, Malefyt reflected on successful client reception of his explicit use of anthropological theory, though he noted that the theory still had to be considerably translated. For example, he explained that he draws on symbolic and interpretive analysis, as well as practice theory, in his work in advertising. He reflected that Victor Turner, Mary Douglas, and "of course" Clifford Geertz are quite helpful in his work - and that his clients "love to hear about symbols and rituals." However, he cautioned that anthropological theories must be "brought down into a condensed or shortened version - translated into an intelligible language 
for the cultural context of business":

What does Bourdieu mean by the habitus? How would you summarize the habitus in ten seconds? What does he really mean by all these structurations and structures of structures, the relation between agency and society? Where is human agency and where does society control? Well, the habitus is the intersection of that. (2014)

I find it striking here that Malefyt has referenced Bourdieu (1990), who I studied in my own theory courses. As a student it might have been helpful to hear the condensed version of Bourdieu before launching into his dense theoretical work. In fact, applying this theory to my own analysis, I might be able to understand the dynamics between agency and social structure contributing to the remarkably patterned "random walks" my informants took from academia into the cultural context of business.

Interestingly, only Morais and Malefyt described clients "loving" hearing about explicit anthropological concepts. Thus, it seems that perhaps certain anthropological theories and business contexts require less "translation" than others. Perhaps, also, certain clients or internal stakeholders might be more open to anthropological theory and concepts than others.

Sometimes, though, translations fail. Smith recalled an experience when she was discussing "phenomenology" with a group of engineers. Rather than explicitly using the term, "phenomenology," she simplified the concept, explaining that "the thing she was talking about is always in relationship to the world." However, her colleagues did not understand that by "relationship to the world," she meant a vague understanding of "world" as "anything outside of you." Rather, to her colleagues, "the world" meant something specific and concrete that she had not intended. In this example, even the "simplified" explanation of the concept failed to translate effectively, indicating the depth of "difference" marked by an anthropological perspective in business, and the particular challenge in translating anthropological theories.

Smith reflected on the challenge of working with others who do not share the same "givens" as they would within an academic anthropology context. Because of this, it is critical for effective communication that she understands "how people are hearing what" she is saying. Then, she explained, "A lot of the work is this translation into different terms and figuring out what this part of my team needs in order to do what they need to do" (2014). Clearly, much cultural knowledge and translation is condensed into the term "work" for anthropologists in business!

According to Smith, these challenges in communication are an ongoing "learning process." Moreover, she explained that the acts of translation and failures in effective communication go in the reverse 
direction sometimes as well: designers or engineers will say something to her that doesn't even "sound like English" from her perspective (2014). Perhaps these engineers could use a course in participant-observation and learning to understand a "foreign" culture. This account represents another case in which everyone is not speaking the "same" English. Moreover, Smith's comments suggest that even subcultures within "business English" are not the same. However, in order to work effectively in collaboration, all must find a common communicative ground.

\section{Ruminations}

Though not explicitly in their job descriptions, anthropologists must essentially conduct fieldwork initially and ongoing to even begin to understand how to successfully perform in their new business roles. Not unlike fieldwork on native festival cycles or on ideas of ownership among hunter-gatherers in Papua, New Guinea, the anthropologist must understand an initially foreign entity: the business. Anthropologists must learn new values, new social roles and power hierarchies, and new linguistic and communication norms. In short, they must learn a new culture.

Then, they need to use knowledge of this community not just to write about it, but, rather, to understand how to survive and thrive as a new member of it. They must learn how to contribute, to be valued, and to be "heard." Remarkably, even though anthropologists typically are initially "clueless" as to business, and business people often do not understand anthropologists (a topic to be taken up in the next article), traditional academic anthropological training should be the best of any discipline in equipping anthropologists with the tools to understand their new context.

At the same time, their traditional education serves as somewhat of a handicap: its communicative terms and forms are unintelligible and, therefore, not valuable to most non-anthropologist business people. Yet, many anthropologists point out that the uniqueness of their language, training and approach to understanding is precisely what gives them the potential to add phenomenal value in business. However, in order to do so successfully, anthropologists must learn how to "translate" into terms and products "relevant" to their colleagues and employers. These acts of translation seem most difficult, and most necessary, in the context of anthropological theory.

It was astounding that despite all of the challenges faced upon integrating into new business cultures, virtually all of my twenty informants clearly did not want to fully become "business people." Rather, they wanted to be "anthropologists in business." This desire for retention of their academic anthropology education, perspectives and identities came across powerfully in a number of my informants' discussions about 
the challenges in learning how to communicate. It is this retention of their anthropological culture in their new cultural context that enables them to serve as "professors" of anthropology to the non-anthropology world outside of academia.

In the next piece, I will explore the challenging role of anthropologists in business -- often misunderstood and counter to "common sense" in their cultural contexts of business. In addition to the anthropologists' task of engaging in fieldwork to understand their new business contexts, they also must make themselves understood and valued by business people. As was previewed in the discussion of many of my informants' challenges (but desires!) to strike a balance between business relevance and anthropological uniqueness, in proceeding articles, I will take up the distinctive value anthropologists can contribute in business - which surprisingly hinges completely upon their traditional academic theoretical training!

Moreover, I will explore the ways by which anthropologists not only leave academia for their "second career in learning" as students, but also have the opportunity for a career in teaching academic anthropology through their daily professional endeavors. Effectively, anthropologists can (and some do) become professors of anthropology, though not to anthropology students as they had expected as graduate students, but to business people!

\section{References}

Baker, Kevin.* 2014. Skype Interview. February 4, 2014.

Bell, Genevieve. 2014. Skype Interview. March 12, 2014. https://doi.org/10.1145/2590528.2590531

Bourdieu, Pierre. 1990. The Logic of Practice. Stanford, CA: Stanford University Press.

Brok-Kristensen, Mikkel. 2014. Skype Interview. February 5, 2014.

Denny, Rita. 2014. Skype Interview. January 28, 2014. https://doi.org/10.7748/ns2014.01.28.21.0.2821975

Erickson, Ken. 1999. Postal Modernism and Anthropological Relevance at Hallmark Cards, Inc. Anthropology News 40(2):6. https://doi.org/10.1111/an.1999.40.3.17

Geertz, Clifford. 1988. Being There. In Works and Lives. Stanford, CA: Stanford University Press.

Hill, Richard.*2014. Skype Interview. February 10, 2014.

Lévi-Strauss, Claude. 1978. Myth and Meaning. New York: University of 
Toronto Press. https://doi.org/10.4324/9780203278871

Mack, Alexandra. 2014. Skype Interview. January 28, 2014.

https://doi.org/10.7748/ns2014.01.28.21.0.2821975

Malefyt, Timothy de Waal. 2014. Skype Interview. February 11, 2014.

Malefyt, Timothy de Waal and Robert J. Morais. 2012. Advertising and Anthropology: Ethnographic Practice and Cultural Perspectives. Oxford: Berg.

Mitchell, Susan.* 2014. Skype Interview. February 13, 2014.

https://doi.org/10.32964/T]13.2

Morais, Robert. 2014. In-person Interview. January 16, 2014.

Sachs-Chess, Patricia. 2014. Skype Interview. January 20, 2014.

Sherry, John. 2014. Skype Interview. January 21, 2014.

https://doi.org/10.1016/S0262-4079(14)60773-9

Smith, Rachel.* 2014. Skype Interview. January 28, 2014.

https://doi.org/10.22233/20412495.0314.38

Squires, Susan. 2014 Skype Interview. January 22, 2014.

Sunderland, Patricia. 2014. Skype Interview. January 26, 2014.

https://doi.org/10.22233/20412495.0914.26

*These interviewees are anonymous per their request.

Elisabeth Powell graduated Phi Beta Kappa and with Highest Honors from Princeton University, where she earned First Prize for her Senior Thesis: "Anthropologists in Business: Teaching Anthropology in the Classroom of Everyday Life." She is a published author and speaker applying her anthropological lens to drive human-centered, global innovation and brand strategy at premier innovation, design and consumer research consultancies. She has added unique value for her clients such as Hilton, Uber, Diageo, Apple, Estee Lauder, Saks Fifth Avenue and Google, and for her firms' cultures and her teammates. Originally from Atlanta, she moved recently to San Francisco from New York to start a new chapter of her own anthropologist in business journey and to explore the natural wonders of the West Coast. 